\title{
Caminhos de justos e perversos. Exegese do Salmo 1
}

Matthias Grenzer ${ }^{1}$

\section{Resumo}

O estudo aqui apresentado dedica-se à descrição da beleza literária e das dimensões teológicas do Salmo 1. Este poema opõe os caminhos dos justos aos caminhos dos perversos, destacando, dessa forma, que somente a insistência na justiça prevista pelas tradições da Torá promete um futuro bom à pessoa, no sentido de poder contar com uma maior produtividade e com a integração na comunidade dos justos.

Palavras-chave: Salmos, Espiritualidade Bíblica, Justiça

\section{Zusammenfassung}

Der hier vorgelegte Aufsatz beschreibt die literarische Schönheit und die theologischen Aussagen des 1. Psalms. Das Gedicht stellt die Wege des Gerechten den Wegen der Perversen gegenüber. Dabei wird hervorgehoben, dass nur das Bestehen auf der in der Tora vorgesehenen Gerechtigkeit jemand eine gute Zukunft verspricht, sowohl im Sinn einer grösseren Produktivität als auch bezüglich der Eingliederung in die Gemeinschaft der Gerechten.

\footnotetext{
${ }^{1}$ O presente estudo foi apresentado, no ano de 2010, aos alunos do Instituto Catequístico da Universidad Católica do Chile. Agradeço, particularmente, ao professor Pe. José Miguel Alvarado Bustamente pelo convite.
} 
Stichwörter: Psalmen, Biblische Spiritualität, Gerechtigkeit

\section{Introdução}

Salmo 1 é a 'porta de entrada' numa 'casa' formada por 150 orações, as quais, juntamente, constituem o livro bíblico dos Salmos. É importante que essa 'porta' não fique fechada, pois, para quem desconhece a 'casa', não se prevê outro lugar de acesso. Além disso, é na 'porta de entrada' que o visitante recebe sua primeira impressão da 'casa' inteira. Ou, com outras palavras: trata-se do lugar da primeira conversa entre o visitante e quem o recebe. Dependendo deste diálogo, o visitante vai entrar de vez na 'casa' ou voltar para trás.

Apresento aqui uma análise literário-teológica do Salmo 1. O estudo encaixa-se em meu projeto de pesquisa sobre as 'As dimensões proféticas da religião do Antigo Israel'. No caso, o interesse dirige-se, de um modo especial, à descrição do compromisso com a justiça que as orações bíblicas querem favorecer em quem adota tais poemas em sua espiritualidade. ${ }^{2}$

\section{Resistência à malvadeza}

1a Feliz o homem

$1 \mathrm{~b} q u e$ não andou conforme o conselho dos perversos,

1c não parou no caminho dos pecadores

$1 \mathrm{~d}$ e não se sentou no assento dos zombadores.

O início do Salmo 1 caracteriza-se pela presença numerosa de pessoas más. O texto menciona perversos, pecadores e zombadores. Não se trata de desconhecidos, pois diversos outros textos bíblicos falam deles.

O perverso, nas tradições da Sagrada Escritura, é quem mostra um comportamento negativo, no sentido de desfavorecer a comunidade. É aquele que, por meio de suas palavras e/ou seus atos, se torna culpado, ameaçando a vida de inocentes. Isso porque o perverso trama contra o justo, [...] a fim de fazer cair o oprimido e o pobre, ou seja, para degolar os homens retos (S1 37,12.14).

Além disso, seja lembrado que, na cultura do Antigo Israel - assim como em todo o Antigo Oriente —, não existe oposição entre a vida profana e a vida religiosa da pessoa. Portanto, o comportamento em relação ao pró-

2. Veja outros dois estudos de minha autoria: Matthias GrenZER, Ação inversora do destino dos pobres. Um estudo do Salmo 113; Matthias Grenzer, As tarefas da cidade. Exegese do Salmo 122. 
ximo influencia a relação com Deus. O paralelismo criado entre perversos e pecadores (cf. v. 1b.c) reforça essa compreensão da realidade. Nesse sentido, as tradições do Antigo Testamento qualificam a falta de solidariedade com os mais necessitados como pecado, avaliando essa postura como não correspondente à vontade do SenHor Deus.

A terceira palavra que ajuda a criar o paralelismo nos meios-versículos 1b.c.d descreve os maus como zombadores. Nos textos paralelos, os zombadores aparecem como pessoas arrogantes que agem no ardor de sua insolência (Pr 21,24). Responsáveis por rixas, litígios e humilhações, agitam a cidade (cf. Pr 22,10; 29,8). Conseqüentemente, o zombador não anda com os sábios (Pr 15,12). Pelo contrário, quem tenta corrigir um zombador, apenas receberá humilhação e ódio como reação dele (cf. Pr 9,7-8).

A crítica do Salmo 1 à sociedade, porém, vai ainda mais longe. Além de caracterizar os malvados como perversos, pecadores e zombadores, o poeta deixa claro que essa gente age de forma planejada. A palavra hebraica conselho (cf. v. 1b) poderia ser traduzida também por estratégia, desígnio, projeto ou idéia. Quer dizer, os maldosos atuam de forma consciente. Seus crimes são altamente qualificados.

Outras duas imagens ainda marcam a descrição das pessoas más no primeiro versículo. A metáfora do caminho (cf. v. 1c) parece reforçar a idéia de que a atuação de

tais pessoas inclui processos históricos mais abrangentes. A imagem do

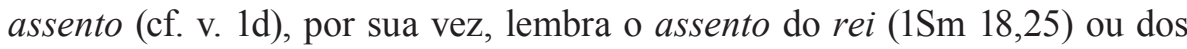
chefes mais proeminentes

numa cidade (cf. Jó 29,7.25). Quer dizer, traz-se à memória o lugar de honra e, com isso, a posição decisiva e influente que alguém pode ocupar numa sociedade.

Resumindo: o início do Salmo 1 deixa perceber uma situação em que um grande número de pessoas más — perversos, pecadores e zombadores chega a dominar a vida da sociedade.

Não obstante, em oposição a toda essa gente decidida a promover o mal, encontra-se uma única pessoa que o poeta chama de homem feliz (cf. v. 1a). Este se mostra resistente. Um triplo não (cf. v. 1b.c.d) marca sua postura. Em todas as situações de sua vida - quer dizer, andando (v. 1b), parado, ou, literalmente traduzido, estando de pé (v. 1c), e sentado (v. 1d) - não faz companhia a seus conterrâneos que optaram por outros caminhos e assentos. 
Por outro lado, porém, esse homem feliz e justo (cf. v. 6a) está sozinho. Fala-se dele no singular. Parece que "sua decisão de vida o transformou em uma raridade". ${ }^{3}$ Nasce, assim, a dúvida sobre sua sobrevivência. Com outras palavras: como alguém pode manter-se como pessoa, quando está decidido a abandonar o "mundo", ou seja, quando se opõe aos valores negativos que, muitas vezes, dominam a convivência na sociedade? O Salmo 1, assim como o conjunto dos 150 Salmos, parece ter sido composto para consolar e, sobretudo, motivar (!) esse tipo de gente.

\section{Paixão pela libertação dos oprimidos}

2a Pelo contrário: seu prazer está no ensino do SENHOR

$2 \mathrm{~b}$ dia e noite murmura o ensino dele.

O homem feliz do Salmo 1 não é uma pessoa que apenas sabe dizer não (cf. o triplo uso da negação não no v. 1b.c.d). Não limita sua vida a uma postura de oposição e resistência ante os perversos, pecadores e zombadores. Por mais que tenha mostrado exatamente essa atitude no decorrer de sua vidaobserve que os verbos em v. 1 se referem ao passado! - , por detrás desse comportamento encontra-se uma motivação positiva. Com outras palavras: o protagonista do Salmo 1 é alguém capaz de sentir prazer (cf. v. 2a), e isso durante o dia e durante a noite(cf. v. 2b).

Mas prazer em quê? De forma realçada, v. 2 apresenta a resposta para essa pergunta tão central, colocando, por duas vezes, o conceito ensino. Mais especificamente, o texto fala do ensino de SENHOR (v. 2a) e, logo em seguida, do ensino dele, ou seja, do ensino cuja autoria se atribui, em última instância, ao Deus de Israel (v. 2b).

Em vista da importância desse termo para a compreensão do Salmo 1, é bom insistir num estudo mais exato. Ensino é a tradução da palavra hebraica Torá. Seria também possível traduzir Torá por instrução. Para o autor do Salmo 1 - assim como para a comunidade de seus ouvintes israelitas esse ensino encontra-se, fixado por escrito, nos cinco livros de Moisés, cujo conjunto os cristãos chamam de Pentateuco. Trata-se, na realidade, dos livros bíblicos Gênesis, Êxodo, Levítico, Números e Deuteronômio.

${ }^{3}$ Norbert LoHFinK, Die Einsamkeit des Gerechten, p. 165. 
Numa leitura mais atenta da Torá descobre-se que o ensino de Israel é marcado por uma estrutura dupla. De um lado, tem-se aí, em forma de narrativas poéticas, a história da salvação. Após ter contemplado as origens do mundo e da humanidade em Deus (cf. Gn 1-11), a Torá ou o Pentateuco apresenta, por primeiro, os inícios do povo bíblico nas figuras dos patriarcas Abraão, Isaac e Jacó - e das matriarcas - Sara, Rebeca, Lia e Raquel -, assim como nos doze filhos de Jacó (cf. Gn 12-50). A realização da dupla promessa de descendência e posse da terra, feita por Deus aos patriarcas, acompanhará, para sempre, o caminho do povo eleito. O que, por sua vez, se iniciou nas tradições dos patriarcas, tem continuidade nos últimos quatro livros da Torá, os quais se dedicam a narrar a história do êxodo. Conta-se que o Senhor Deus libertou seu povo da escravidão no Egito e o conduziu maravilhosamente, pelo meio do deserto, a fim de favorecer sua instalação nas terras de Canaã. Dessa forma, cumpre-se a antiga promessa do SENHOR de dar aos descendentes de Abraão, Isaac e Jacó a posse da terra.

Por outro lado, inserido no meio das narrativas poéticas, a Torá contém um abundante material jurídico. Tendo em vista que é Moisés quem, dentro da história do êxodo, recebe as leis do SENHOR e/ou as anuncia ao povo, pode-se falar de "leis mosaicas". Não obstante, observando o conteúdo das leis — sobretudo o contexto sócio-econômico pressuposto nelas - , fica claro que essas formulações jurídicas são de épocas posteriores ao momento do êxodo histórico, o qual, geralmente, se procura no final do século XIII a.C. Contudo, determinante foi o fato de que os legisladores israelitas, em busca de justiça, se inspiraram, sempre de novo, na experiência do êxodo, ou seja, no SENHOR Deus que fez seu povo sair da terra do Egito, isto é, da casa da escravidão (cf. Ex 20,2). Dessa forma, pode-se afirmar que as leis mosaicas realmente são fruto do êxodo, pois o objetivo principal delas é transformar a experiência da libertação da escravidão em um projeto jurídico, que quer garantir a construção de uma sociedade nova e justa. Com outras palavras: as leis da Torá são a tentativa de proteger, juridicamente, aquela liberdade com a qual o SENHOR presenteou seu povo, no momento em que adotou os oprimidos pelo sistema faraônico como filhos (cf. Os 11,1). Assim, dentro da perspectiva teológica, as leis da Torá pertencem, de fato, à história do êxodo e a Moisés.

Mais uma vez: a Torá é marcada por uma estrutura dupla. Trata-se da história da salvação do povo israelita, a qual se concretiza, posteriormente, num projeto jurídico que quer servir à construção de uma sociedade justa. Observando o volume do texto, a metade dos 187 capítulos do Pentateuco se 
constitui por narrativas poéticas, sendo que a outra metade é formada por leis. No entanto, mais importante ainda é que ambas as partes, quanto ao conteúdo, formam uma unidade indissolúvel.

Por isso, seria errado definir o conjunto da Torá - e, por conseqüência, traduzir a palavra Torá — como "lei", algo que acontece em diversas traduções do Salmo 1. Mais correto é falar de ensino ou de instrução, pois, no caso da Torá, trata-se de um amplo ensino que se forma a partir de uma experiência histórica de libertação - no sentido de que o projeto do êxodo representa a vontade salvadora do SENHOR Deus em favor do povo dos oprimidos - e a concretização dela em um direito. Juntas, as duas partes estabelecem o ensino, o qual quer definir o rumo do povo bíblico para todos os tempos.

Voltando à interpretação do Salmo 1, chama a atenção do leitor que o salmista insiste na relação entre a felicidade do homem (v. 1a) e o prazer que este sente com o ensino, ou seja, com a Torá do SENHOR (cf. 2a). Tendo consciência do projeto favorecido por esse ensino, pode-se afirmar o seguinte: feliz $O$ homem que é capaz de se prender à proposta mosaica de uma sociedade alternativa, sendo esta última marcada por relações mais igualitárias e justas. Mais ainda: feliz o homem que consegue, conforme o ensino das tradições do êxodo, imaginar a construção de uma sociedade nova a partir dos e pelos oprimidos, uma vez que estes estejam dispostos a corresponderem à vontade libertadora do SENHOR Deus e a confiarem nele como soberano de toda a história.

Observando, por sua vez, a realidade do dia-a-dia, no Salmo 1 também já se sabe que o modelo da sociedade alternativa ainda não foi colocado em prática. Pelo contrário, o salmista participa da experiência de que a caminhada histórica do povo eleito é marcada por sucessivas desistências do projeto previsto no ensino de SENHOR, causadas, em geral, pelos interesses particulares da classe dirigente. Por enquanto, perversos, pecadores e zombadores (cf. v. 1b-d) parecem dominar a convivência entre as pessoas.

Mesmo assim, ou talvez até por causa dessa circunstância, o modelo de comportamento proposto pelo Salmo 1 torna-se mais importante ainda: dia $e$ noite, deve-se murmurar o ensino do SENHOR (v. 2b). Talvez esta seja a única alternativa para o fiel em épocas de maior resistência ao projeto de Deus, querendo combater os sentimentos de isolação e solidão. Sendo repetidas, pois, de forma ininterrupta, as tradições do êxodo, não se perde facilmente a esperança que nasceu junto à experiência da libertação da escravidão no Egito. É uma forma de manter o mundo alternativo presente, ao menos em voz baixa, ou seja, como mundo murmurado. 
A palavra murmurar indica, nesse contexto, um falar para fora e, ao mesmo tempo, para dentro de si, a fim de acolher plenamente o ensino do SENHOR. ${ }^{4}$ Com outras palavras: meditando, a pessoa estabelece um mundo imaginado, em contraste com aquele que vive. Isso, porém, não significa que o mundo murmurado não exista, pois o Salmo 1 até afirma a dependência da felicidade do homem para com esse mundo imaginado.

$\mathrm{Na}$ realidade, todos murmuram. Há línguas que murmuram maldade (Is 59,3) e falsidade (Jó 27,4), ou corações que murmuram violência (Pr 24,2). Existem os companheiros que murmuram mentiras (S1 38,12-13). No entanto, conforme a fé do Antigo Israel, todos eles serão como as nações que murmuram em vão (Sl 2,1).

O Salmo 1, no entanto, estabelece um modelo contrário. Paralelamente ao pedido feito a Josué — o sucessor de Moisés! —, a proposta consiste em murmurar, dia e noite, o livro da Torá (cf. Js 1,8). Dessa forma, murmura-se a justiça (Sl 35,28; 71,24) e as obras do SENHOR (Sl 77,13; 143,5), respectivamente, a verdade $(\operatorname{Pr} 8,7)$ e a sabedoria $(\mathrm{Sl} 37,30)$.

Afinal, a idéia de a pessoa desenvolver uma verdadeira paixão pelo ensino de SENHOR encontra sua última razão na qualidade e na finalidade dessa instrução, pois se afirma que a Torá do SENHOR é perfeita e capaz de devolver $o$ alento à pessoa humana (cf. Sl 19,8). Uma vez que a vida confirme essa experiência, realmente pode-se afirmar: Felizes os que andam conforme a Torá do SENHOR (Sl 119,1) e se comprazem muito com seus mandamentos (cf. Sl 112,1).

\section{A produtividade do justo}

3a Será como uma árvore plantada junto a canais de água,

3b que dá seu fruto a seu tempo

$3 \mathrm{c}$ e cuja folhagem não murcha.

3d Tudo o que faz terá êxito.

A linguagem abstrata cede lugar à linguagem metafórica que trabalha com imagens. O poeta responsável pela autoria do Salmo 1 compara agora o homem apaixonado pelo ensino do SENHOR a uma árvore cheia de vida. Por ser plantada junto a canais de água (v. 3a), essa árvore produz seu fruto no

${ }^{4}$ Cf. Erich Zenger, Mit meinem Gott überspringe ich Mauern, p. 45. 
tempo certo (v. 3b) e, já ultrapassando os limites da natureza, não permite que sua folhagem murche (v. 3c).

$\mathrm{Na}$ realidade, trata-se de uma imagem complexa, formada por vários elementos: estão presentes uma árvore, canais de água, frutos e folhagem. $\mathrm{O}$ conjunto da imagem revela a estima da cultura do Antigo Israel, assim como das diversas culturas do Antigo Oriente, pelas árvores e, em especial, pelas árvores frutíferas. Basta lembrar como os reis e as pessoas mais ricas cuidavam de seus jardins, uma vez que estes ofereciam um excelente conforto.

Observando os detalhes da imagem da árvore produtiva, certos pormenores devem ser explorados em vista das perspectivas teológicas do Salmo 1. Afirma-se, entre outras coisas, que a árvore foi plantada junto a canais de água (v. 3a). Quer dizer, ela não nasceu por si só nesse lugar tão privilegiado. Alguém "a transferiu para lá. Tem-se, portanto, a consciência de que aconteceu um êxodo". 5

Coerentemente, Israel é convidado a compreender-se como resultado desse projeto de liberdade promovido pelo SENHOR. Sua existência nas terras de Canaã tem caráter de presente, pois, conforme suas próprias tradições, foi o apoio do Deus do êxodo que assegurou ao povo dos oprimidos a chegada e permanência na terra prometida. Foi o SENHOR quem plantou Israel junto a canais de água, no meio de outras nações bem mais antigas. O homem fiel ao ensino do Senhor (v. 2a) sabe disso, pois é a própria Torá que o ensina.

A imagem avança ainda mais: trata-se de uma árvore que dá seu fruto a seu tempo (v. 3b). Com isso, afirma-se no Salmo 1 a fé de que o futuro, de fato, pertence a quem se preocupa com a memória religioso-histórica das tradições mosaicas. Basta chegar o tempo certo (cf. v.3b). Além do mais, trata-se de um processo irreversível, algo que não morre mais, assim como a folhagem da árvore não murcha (cf. v. 3c).

A última frase do v. 3 adota novamente a linguagem abstrata: Tudo o que faz terá êxito (v. 3d). O verbo fazer somente pode referir-se ao homem feliz (v. 1a), ou seja, àquele que sente prazer com o ensino do SENHOR (v. 2a). Com outras palavras: o tema continua sendo o destino bem-sucedido do justo solitário. Todavia, a expressão no v.3d abre maior espaço para sua compreensão. Dentro do contexto imediato da frase hebraica, o verbo ter êxito, respectivamente, prosperar, concorda com o substantivo tudo. Portanto, deve-se traduzir como proposto acima: tudo o que faz terá êxito, ou seja, prosperará.

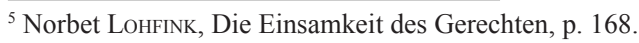


Por outro lado, porém, o leitor pode estar lembrado de que as Sagradas Escrituras falam também que o SENHOR deixa ter êxito, no sentido de que é Deus quem faz alguém prosperar (cf. Gn 24,21.40.42.56; 39,3.23; S1 118,25; Ne 1,$11 ; 2,20 ; 2 \mathrm{Cr} 26,5)$. A formulação em v. 3d mantém-se aberta para essa compreensão, uma vez que o SENHOR pode ser subentendido como sujeito oculto. Chegar-se-ia, portanto, à seguinte idéia: Tudo o que o homem preocupado com a Torá faz, o SENHOR deixa ter êxito.

\section{A inutilidade dos perversos}

4a Não são assim os perversos.

4b Pelo contrário: são como a palha que o vento dispersa.

Terminou a primeira parte do Salmo 1, que contempla, centralmente, o personagem e o destino da pessoa preocupada com o ensino do SENHOR. V. 4 inicia a segunda metade do Salmo, na qual são meditados, sobretudo, os perversos e o futuro deles.

Olhando a forma literária do Salmo 1, chama a atenção do leitor que o final da primeira parte, após um discurso em linguagem abstrata (v. 1a2b), trouxe a metáfora da árvore bem-sucedida (v. 3a-c). V. 3d, por sua vez, fechou a seção sobre o homem feliz novamente com uma formulação abstrata. A segunda metade do Salmo 1 trabalha de forma simetricamente oposta. Introduzida por uma curta frase abstrata (v. 4a), a metáfora da palha que o vento dispersa (v. 4b) torna-se marcante no início. Em seguida, v. 5a-6b levam Salmo 1 até seu final, adotando, outra vez, linguagem abstrata.

Descobre-se, portanto, a seguinte disposição concêntrica:

A Discurso abstrato sobre a realidade (v. 1a-2b)

B Uma imagem (v. 3a-c)

[discurso abstrato (v. 3d-4a)]

B' Uma imagem (v. 4b)

A' Discurso abstrato sobre a realidade (v. 5a-6b) ${ }^{6}$

A imagem da palha que o vento dispersa (v. 4b; cf. também S1 35,5; Jó 21,18 ) contrasta fortemente com a metáfora da árvore que dá ao homem seu

$\overline{{ }^{6} \text { Hans-Winfried JÜNGLING, Salmos 1-41, p. } 717 .}$ 
fruto para comer e sua folhagem para se ter sombra (v. 3a-c). A palha, por sua vez, após ter cumprido sua função no processo de crescimento do grão, não é mais útil ao homem. Ela simplesmente sobra como debulho quando se extraem os grãos da espiga. A partir de agora, somente dá trabalho, pois precisa ser separada das sementes, a fim de que essas possam servir para a fabricação da farinha. A sociedade agrícola do Antigo Israel estava até familiarizada com a imagem do trabalhador jogando os grãos para o alto, a fim de deixar $o$ vento dispersar a palha.

Contudo, a metáfora em v.4b parece indicar a inutilidade dos perversos, uma vez que seu comportamento culposo os torna inaproveitáveis no processo da construção de uma sociedade alternativa, a qual encontra suas metas na experiência da libertação dos oprimidos, ou seja, nas tradições do êxodo.

\section{O sumiço dos perversos nos tribunais}

5a Por isso: os perversos não se levantarão no julgamento,

$5 \mathrm{~b} \quad$ nem os pecadores na assembléia dos justos.

Reassumindo a linguagem abstrata, o salmista continua descrevendo o destino dos perversos. Dois paralelismos marcam v. 5. Primeiramente, os perversos aparecem, outra vez, ao lado dos pecadores (cf. v. 1b-c). Em segundo lugar, as expressões no julgamento e na assembléia dos justos levam o leitor ao mesmo ambiente do judiciário. A circunstância de que um único verbo conduz todo o versículo - cf. a expressão não se levantarão em v. 5a - causa ainda maior proximidade entre as formulações paralelas.

Por mais clara, porém, que seja a forma poética do versículo, o texto impõe agora a seguinte questão em relação as suas perspectivas teológicas: a qual momento o salmista se refere em v.5? Será que o poeta fala do julgamento realizado no portão da cidade israelita, quando os homens livres de um lugar formam a assembléia do tribunal, propondo-se a decidir os litígios? Ou está em vista algum tipo de juízo final, promovido, após a morte, por Deus nos céus?

A resposta a tal pergunta é decisiva para outras dúvidas que a pessoa humana — sobretudo o justo perseguido — apresenta com muita urgência. Por exemplo: pode-se esperar por um momento na história deste mundo em que os perversos não influenciem mais, de forma negativa, a procura da justiça? $\mathrm{Ou}$ por assembléias formadas apenas por justos? E como Deus participa ou não desse processo tão desejável? 
Na procura de uma resposta para essas questões, é importante observar que o Salmo 1 "não descreve uma condenação dos perversos por parte de Deus" (confira também v. 6). Isso, por sua vez, se pressuporia caso o texto quisesse apresentar o juízo final. Torna-se, portanto, mais provável que o salmista sonhe mesmo com a transformação do mundo em que vive. $\mathrm{Ou}$ seja: numa perspectiva intramundana, o objetivo é prever a formação de uma sociedade em que os perversos fiquem sem voz nos grêmios decisivos.

Afinal, as duas perspectivas nem se excluem, pois "como todo o saltério também Salmo 1 se mantém aberto em seu anúncio para o fim dos tempos. O que está sendo dito pode fazer referência ao futuro pertencente à história deste mundo como ao futuro que transcende este mundo. [...] Apenas uma coisa deve saber-se: temos uma esperança enorme e caminhamos em direção a ela. No entanto, como será e quando se realizará, não sabemos. Apenas alcançamos essa esperança através de imagens". ${ }^{\circ}$

\section{A relação entre Deus e os justos}

6a Pois o SENHOR é quem conhece o caminho dos justos:

$6 \mathrm{~b}$ o caminho dos perversos, porém, perece.

V. 6 tem caráter de resumo. Define por quê os justos têm futuro. E declara o fim dos perversos.

A forma literária do versículo oferece, novamente, as primeiras pistas para a compreensão de seu conteúdo. Bem visível é o paralelismo entre $o$ caminho dos justos (v. 6a) e o caminho dos perversos (v. 6b; cf. também a presença do motivo do caminho em v. 1c). Com isso, a oposição que marcou todo o Salmo 1 é outra vez realçada. Mais ainda: os opositores do homem preocupado com o ensino de SENHOR aparecem agora pela sétima vez, sendo que esse número é usado como elemento estilístico pelos poetas hebreus. Veja a seqüência: perversos (v. 1b), pecadores (v. 1c), zombadores (v. 1d), perversos (v. 4a), perversos (v. 5a), pecadores (v. 5b) e perversos (v. $6 \mathrm{~b})$. Em contrapartida, a presença dos justos é mais rara. No início, tem-se um único homem feliz (v. 1a), o qual resiste a uma multidão de malvados, caindo assim numa grande solidão. No final do Salmo 1, porém, o fiel ao ensino do SENHOR não está mais sozinho. Agora o salmista fala, no plural,

\footnotetext{
${ }^{7}$ Claudia Sticher, Die Rettung der Guten durch Gott und die Selbstzerstörung der Bösen, p. 66.

${ }^{8}$ Norbert Lohfink, Die Einsamkeit des Gerechten, p. 169-170.
} 
dos justos como um grupo (v. 5b.6a). Ou seja: o justo conseguiu formar sua comunidade.

Marcante também é que, apenas em v. 6a, o SENHOR atua pela primeira vez. Antes disso, o nome do Deus de Israel estava presente somente em v. 2a, quando o assunto foi o ensino, quer dizer, ou seja, a Torá do SENHOR. Agora, por sua vez, se afirma que o SENHOR é conhecedor do caminho dos justos. No texto hebraico do Salmo, trata-se de uma frase nominal, que chama a atenção do leitor pela ausência de um verbo finito. Com isso, a frase não é ligada a um determinado momento histórico. Muito mais, seu caráter é afirmar algo que vale sempre, no sentido de que o SENHOR, em princípio ou eternamente é aquele que conhece o caminho dos justos.

A palavra conhecer merece maior atenção. Indica-se, com esse termo, a comunhão mais íntima possível, inclusive a relação íntima do ato sexual entre homem e mulher. Da mesma forma, o verbo conhecer marca a história entre o SENHOR e seu povo. Por excelência, há de se lembrar Ex 2,23-25, onde se descreve a decisão divina de realizar o êxodo: Deus escutou seus gemidos [...], Deus viu os filhos de Israel e Deus (os) conheceu. Em relação ao Salmo 1 , portanto, vale dizer que "o caminho do justo, em última instância, alcança êxito não por causa do esforço dele mesmo, mas porque o SENHOR o conhece, ou seja, o acompanha de forma preocupada e amável". ${ }^{9}$

Por outro lado, de forma bem diferente, Salmo 1 afirma agora que $o$ caminho dos perversos perece (v. 6b). O verbo hebraico também poderia ser traduzido como desviar-se ou andar perdido. Importante,no entanto, é a observação de que, nesse caso, não se descreve uma ação de Deus. "Conforme à visão do Salmo, Deus se preocupa apenas com o justo, uma vez que fica em aberto até que ponto ele tem a ver com o fracasso e o perecimento do perverso". ${ }^{10}$ Com outras palavras: "Ao nada em que o perverso se afunda [...] Deus não colabora de modo algum. A própria lógica deste mundo o leva à auto-dissolução. Ou, como diz a imagem no meio do Salmo, os ventos da história levam o perverso em direção ao inalcançável. ${ }^{11}$

Dessa forma, a situação inicial do Salmo 1 se inverteu: a multidão dos malfeitores desapareceu, enquanto o homem fiel ao ensino do SENHOR está sendo integrado na comunidade dos justos.

\footnotetext{
${ }^{9}$ Erich ZENGER, Mit meinem Gott überspringe ich Mauern, p. 46.

${ }^{10}$ Claudia Sticher, Die Rettung der Guten durch Gott und die Selbstzerstörung der Bösen, p. 66.

${ }^{11}$ Norbert Lohfink, Die Einsamkeit des Gerechten, p. 170.
} 


\section{Conclusão}

Salmo 1 marca seu lugar - literariamente tão realçado no início do livro dos Salmos - de forma bem definida. Defende o pensamento de que o homem, para alcançar a felicidade e ter êxito em tudo que faz, deve mostrar-se resistente à malvadeza e apaixonar-se pelo projeto da libertação dos oprimidos, de acordo com as tradições do êxodo. ${ }^{12}$

O destino dos que optam pela perversidade, porém, será outro. Os ventos da história, pois, encarregar-se-ão para levá-los embora. Mais ainda: é dessa forma que se aproxima um tempo futuro, no qual as assembléias serão formadas somente por justos.

No entanto, há de se observar o detalhe mais importante: Salmo 1 cultiva a ideia de que se precisa de Deus para chegar a este tempo. Pois somente a esperança de que o SENHOR conheça o justo, garantindo-lhe a vitória sobre os perversos, justifica a visão de um futuro melhor para toda a sociedade.

\section{Referências Bibliográficas}

Fernandes, L. A.; Grenzer, M. Êxodo 15,22-18,27. São Paulo, Paulinas, 2011. (Coleção: Comentário Bíblico Paulinas).

Grenzer, M. Ação inversora do destino dos pobres. Um estudo do Salmo 113. In: Atualidade Teológica, n. 36, a. 2010, p. 441-452.

As tarefas da cidade. Exegese do Salmo 122. In: Afonso M. L. Soares; João Décio Passos (org.). A fé na metrópole. Desafios e olhares múltiplos. São Paulo, Paulinas, 2009. p. 265-281.

Jüngling, H. W. Salmos 1-41. In: FARMER, W. R. Comentario Bíblico Internacional. Comentario católico e ecumémico para el siglo XXI. Estella (Navarra), Verbo Divino, ${ }^{2} 2000$.

Lohfink, N. Die Einsamkeit des Gerechten: Zu Psalm 1. In: Im

Schatten deiner Flügel. Grosse Bibeltexte neu erschlossen. Freiburg, Herder, 1999.

Sticher, C. Die Rettung der Guten durch Gott und die Selbstzerstörung der Bösen. Ein theologisches Denkmuster im Psalter. Berlin, Philo, 2002. (Coleção: Bonner Biblische Beiträge, 137).

${ }^{12}$ Cf. Leonardo Agostini Fernandes; Matthias Grenzer, Êxodo 15,22-18,27. 
Matthias Grenzer

Doutor em Teologia Bíblica pela Faculdade de Filosofia e Teologia St. Georgenem Frankfurt am Main, Alemanha. Professor de Teologia Bíblica na Faculdade de Teologia da PUC-SP.

Artigo Recebido em 21/06/2011 Artigo Aprovado em 29/07/2011 